\title{
Liver transplantation and quality of life
}

\author{
J Rodés MD FRCP, M Navasa MD
}

\begin{abstract}
J Rodés, M Navasa. Liver transplantation and quality of life. Can J Gastroenterol 2000;14(8):693-699. To date, more than 50,000 liver transplantations have been performed around the world; the survival rate five years after transplantation ranges from $60 \%$ to $65 \%$. One of the fundamental objectives for liver transplantation teams is to achieve the best possible quality of life (QOL) for the patients.

A concise analysis of the methodology used (15 questionnaires) to measure QOL of patients with liver transplants is described. The authors suggest that now is the time to establish a database so that a validated instrument will be available to compare QOL results from all the liver transplantation programs.

Liver transplantation is believed to improve QOL, although there are several problems with some of the papers published on this subject. Some studies are retrospective, whereas in others, patients in bad physical conditions are excluded from the study; in quite a few prospective studies, deaths are not included in the data analysis.

Finally, the authors provide a brief, concise analysis of late complications and of recurrence of the disease after liver transplantation, which influence QOL.
\end{abstract}

Key Words: Liver transplantation; Quality of life

\section{Transplantation hépatique et qualité de vie}

RÉSUMÉ : À ce jour, plus de 50000 transplantations hépatiques ont été effectuées dans le monde. Le taux de survie, cinq ans après la transplantation, varie de 60 à $65 \%$. L'un des objectifs fondamentaux des équipes de transplantation du foie est d'obtenir la meilleure qualité de vie possible pour leurs patients.

On décrit ici une analyse concise de la méthodologie utilisée (15 questionnaires) pour mesurer la qualité de vie des greffés du foie. Les auteurs suggèrent qu'il faut désormais mettre sur pied une base de données pour accéder à un instrument validé nous permettant de comparer les résultats au chapitre de la qualité de vie auprès de tous les programmes de transplantation hépatique.

On croit que la transplantation hépatique améliore la qualité de vie, malgré certaines lacunes notées dans les articles publiés à ce sujet. Certaines études sont rétrospectives alors que d'autres ont exclu des patients qui étaient en mauvaise santé. Dans quelques études prospectives, les décès ne sont pas inclus dans l'analyse des données. En dernier lieu, les auteurs proposent une analyse concise des complications tardives associées à la récurrence de la maladie après la greffe du foie, ce qui influe sur la qualité de vie.
A fter the Consensus Conference of the National Institutes of Health held in Washington, DC, in 1983 (1), orthotopic liver transplantation (OLT) has become a regulated surgical procedure for many surgeons with sufficient experience and training. The number of centres with the capacity to carry out this surgical procedure successfully has increased extraordinarily in recent years. Furthermore, the survival of patients after liver transplantation is very high in Europe, the United States and Canada. To date, more than 50,000 liver transplantations have been performed around the world, with survival rates ranging from $70 \%$ to $85 \%$ one year after transplantation, and from $60 \%$ to $65 \%$ five years after transplantation (1). Although the rate of survival of patients undergoing OLT may still rise, at this time, one of the fundamental objectives for liver transplantation teams is to achieve the best possible quality of life (QOL) for these patients. Objective data must be available so that the QOL of patients who have undergone OLT, and the main posttransplant disorders and complications that may influence the patients' QOL, can be better understood. This review provides an analysis of the methodology that has been used to evaluate the QOL of patients who have undergone OLT, the results obtained and the most important complications that may affect the QOL of these patients.

This mini-review was prepared from a presentation made at the World Congress of Gastroenterology, Vienna, Austria, September 6 to 11, 1998

Liver Unit, Institut Clinic de Malalties Digestives, Institut d'Investigaciones Biomèdiques August Pi i Sunyer (IDIBAPS), Hospital Clínic,

Universitat de Barcelona, Barcelona, Spain

Correspondence: Prof Juan Rodés, Villarroel, 170, Barcelona 8036, Spain. Telephone +93-4546000, fax +93-4515522,

e-mail rodes@medicina.ub.es

Received for publication September 9, 1999. Accepted September 13, 1999 


\section{MEASURING QUALITY OF LIFE AFTER LIVER TRANSPLANTATION}

The term 'QOL' is very broad and includes physical and mental status, as well as psychosocial adaptation. Psychosocial adaptation is "the capacity of an individual to perform social and domestic roles so as to meet the challenges of everyday living without emotional distress or physical disability" (2). Nonetheless, the concept of QOL is subject to numerous interpretations because of the lack of clear, precise criteria for its measurement (3). In measuring the QOL of patients to be evaluated for entrance into a liver transplantation program, the opinions of the patients themselves and those of the health care professionals (physicians, psychologists, nurses and social workers) must be considered. Schematically, the indicators of QOL may range from purely psychological aspects (4) and the capacity to return to work (3), to complex questionnaires regarding social activities and psychological problems. The first indicators considered were fundamentally aimed at measuring certain vital activities and, therefore, did not strictly measure QOL. The perception of QOL is not identical for all the patients because cultural, economical, social and individual factors are involved. Measurement of the status of health and measurement of QOL are frequently confused (5). Health status, QOL and functional status are concepts that are generally used indistinctly and comprise, in a broad sense, what is known as 'health' (6). The concept of health in this sense ranges from very negative aspects, such as death, to very positive aspects, such as the love of life, having a normal functional capacity and even feeling truly happy.

It is important to know the patients' QOL because, to a certain extent, it allows the impact that a particular chronic disease may have in a particular patient to be measured (7). The exclusive measurement of physiological functions provides very valid information to the physicians but is of limited interest to the patients and their relatives. Moreover, the data obtained do not usually correlate well with the functional capacity and the well-being of the patients. Another reason why it is important to measure QOL is that, at times, two patients with the same clinical alterations may have totally different responses. All these considerations clearly justify the need for measuring the QOL of patients with chronic disease or for evaluating the results of a determined therapy. Questionnaires comprising a series of questions or items duly designed for a certain domain or dimension are used to measure QOL. The term 'domain or dimension' is the area of behaviour or experience to be analyzed, including mobility, depression, anxiety and well-being, among some possible aspects (8). Usually, the domains analyzed are physical functional capacity, social function (integration) and the measurement of functional capacity, mental health, general perception of health, vitality (energy or fatigue), pain and cognitive function. To the contrary, the clinical and analytical data and those of other explorations (imaging techniques) are only analyzed in very specific studies (8).

There are numerous questionnaires that analyze different domains, and they have been widely used to measure the
QOL of patients with different chronic diseases. These tools should provide sufficient information to determine the measurable psychological disorders that cause a particular disease, the personal functioning, the psychological distress and/or well-being, the general health perceptions from the patients, and the social functioning of the patients. In this overview, however, only the questionnaires and other techniques that are most often used to analyze the QOL of patients undergoing OLT have been included.

The United Network of Organ Sharing: The United Network of Organ Sharing (9) is a relatively simple system used to code the level of a patient's physical function. For example, stage I is defined as the capacity of the patients to go to school or to work normally, and stage VI is defined as the need for mechanical assistance to allow the patient to remain alive.

The Sickness Impact Profile: The Sickness Impact Profile (SIP) (2) is a multidimensional tool that quantifies the status of health in relation to physical, cognitive and functional behaviour aspects that the patient subjectively perceives.

The Index of Well-Being: The Index of Well-Being (IWB) is a weighted average of two components - the Overall Life Satisfaction, which is made up of a single item (How satisfied are you with your life as a whole these days?) and the Index of General Affect, which consists of eight bipolar adjectives, such as interesting-boring or empty-full (10).

The Medical Outcome Survey: The Medical Outcome Survey (MOS) (11) is a brief questionnaire that measures physical and social function, physical and emotional limitations, mental health and the general perception of health.

The Karnofsky performance status scale: The Karnofsky performance status scale is a measurement developed to assess globally the function of patients regarding their normal activity (12). It is an ordinal scale ranging from 100 (normal, ie, no complaints, no evidence of disease) to 0 (death).

The Nottingham Health Profile: The Nottingham Health Profile (NHP) $(11,12)$ is a questionnaire of perceived health that has been widely used in measuring QOL in many groups of patients. The NHP consists of 38 statements that describe possible experiences of health and illness in patients (ie, everything requires an effort, I feel alone with no one close to me) classified into the following six dimensions of health: energy, pain, emotional reactions, sleep, social isolation and physical mobility. The NHP also includes the following seven questions regarding the daily activities of the patients: work, domestic life, social interactions, family relationships, sexual activity, hobbies and holidays. Nevertheless, the NHP is limited to assessing physical function, symptoms and psychological function, and, therefore, cannot address general health perceptions.

The Visual Analogue Scale: The Visual Analogue Scale (13) is a measurement of well-being that is qualified by the patients themselves; the patient indicates the degree of wellbeing. The left side of the scale reflects feeling bad, while the right side of the scale reflects well-being. The total length of the scale is $10 \mathrm{~cm}$. 
The Short Form-36 Health Status Survey: The Short Form-36 Health Status Survey (SF-36) is a 36-item questionnaire that measures general health status. The SF-36 was developed to measure eight of the most important areas of health, which have universal value, and represent the basic functions of humans and feelings of well-being in the broadest sense. These functions include physical activity, vitality, social function, emotional aspects and mental health. Items on the survey are scored from 0 to 100 . The highest scores indicate the best health status; a value of 100 in all areas of health indicates that there are no limitations or problems in each area (14).

The Hospital Anxiety and Depression Scale: The Hospital Anxiety and Depression Scale is a 14-item questionnaire that autoevaluates the mood status of the patient, and is used to measure anxiety and depression. The maximum score is 20 , and a patient who scores over 11 is considered to have significant anxiety or depression (15).

The Beck Depression Inventory: The Beck Depression Inventory is a standardized, 21-item measure of cognitive and affective function, and somatic symptoms of depression (16). The items are scored from 0 to 63 , with the highest qualifications indicating major depression (17).

The Profile of Mood States Scale: The Profile of Mood States Scale is a 65-item tool that globally measures the alterations in mood status and six types of emotions - anger and hostility; stress and anxiety; depression and dejection; vigour and activity; confusion and bewilderment; and fatigue and lack of energy. The highest scores indicate a very large alteration in the mood status of the patient (18).

The Ways of Coping Scale: The Ways of Coping Scale is an inventory of coping with illness styles used to assess how an individual copes with the general stress of being ill or adapts in the face of chronic illness. A higher score means that the patient adapts poorly (17).

The National Institute of Diabetes and Digestive and Kidney Diseases Liver Transplant Database QOL survey: The adult version of the National Institute of Diabetes and Digestive and Kidney Diseases (NIDDK) Liver Transplant Database (LTD) QOL survey was developed to measure QOL and health status from the perspective of the patient. This questionnaire has a modular format and includes global QOL measurements and subjective data on the health status of the patient, as well as specific symptoms of liver disease or as a consequence of liver transplantation. The concept was based on the 'bottom-up' theory of the QOL, which proposes that global QOL is the sum of the individual opinions of the patients regarding the most important aspects of life, such as family, health and income (19-23).

The LTD QOL: The LTD QOL is an extensive questionnaire that was developed as a consequence of a longitudinal multicentre study on QOL after OLT. The study was supported by the NIDDK. The questionnaire covers all the domains of QOL described by Ware (23) and is the only tool that specifically measures the QOL of liver transplantation patients. The questions comprising the questionnaire were taken from several questionnaires that have already been validated for measuring QOL, such as the Karnofsky scale, NHP, SIP, IWB and MOS. Although this questionnaire has already been used in two studies, it has not, as yet, been completely validated $(20,22)$.

The European Organization for Research and Treatment of Cancer QOQ-C: The European Organization for Research and Treatment of Cancer QOQ-C is a short questionnaire (30 items) covering functional domains (physical, role, emotional, cognitive and social functioning) and symptomoriented scales (fatigue, pain, nausea, gastrointestinal symptoms and others) (24).

The methods for measuring QOL briefly described here have been validated, with the exception of the LTD QOL. However, given the disparity of the tools used in the published studies, the establishment of a database is important because it would allow comparison of the results obtained on QOL from all the liver transplantation programs. This is particularly important because the concept of QOL is still not well defined and not all the investigators have the same criteria for measuring QOL. Moreover, although the tools used are excellent and have been validated, they are not standardized, and the best way to analyze the data obtained is not known. These aspects are essential because the studies published to date are difficult to compare. The LTD QOL questionnaire will probably be the best method for measuring QOL in liver transplantation patients, although more information is required to make this conclusion $(25,26)$.

\section{DOES LIVER TRANSPLANTATION IMPROVE QOL?}

Guyatt et al (27) proposed that the fundamental question that clinicians should ask about QOL is, "Will this treatment make my patients feel better?". In the case of liver transplantation, the answer is yes. Most studies of the QOL of patients who have undergone OLT demonstrate that more than $80 \%$ of patients are able lead normal lives. School-aged patients return to school, and their somatic development and psychological development are completely normal. Adult patients are able to return to their family responsibilities, social lives return to normal and some patients go back to work. In addition, despite having to receive immunosuppression treatment for life, in most cases, many men have successfully fathered children, and many women have become pregnant and given birth to healthy children. However, it is important to point out that spontaneous abortions, premature births and cesarean sections are relatively frequent in women who have undergone liver transplantation (1).

By analyzing the studies published on QOL after OLT, it is possible to detect aspects that impede valid, indisputable conclusions. Some studies are retrospective. In others, patients in bad physical condition are excluded from the study, and in quite a few prospective studies, deaths are not included in the data analysis. All of these factors may influence the results and may positively magnify the effect of liver transplantation on the patients' QOL (26). Lastly, the evaluation of QOL should be performed at least once, one 
year after transplantation, because, by this time, the patient has stabilized clinically (27).

Liver transplantation results in the disappearance, or at least improvement, of symptoms related to the underlying liver disease. The pruritus and profound asthenia of patients with chronic cholestasis, the hepatic encephalopathy, jaundice, ascites and other related symptoms are reversed by the implantation of a new liver. Likewise, patients have fewer health problems and few functional limitations. All studies observed an improvement in sexual function, mobility and social life (28). Nonetheless, the QOL of patients who undergo liver transplantation is lower than that of the general population (29). In a prospective study, patients who underwent liver transplantation were found to have health limitations. Seven per cent of the patients had more difficulties in their vacation period and $14 \%$ in their sex life compared with an age- and sex-matched general population sample (30). In other studies, patients who received a liver transplant often had other limitations at work, in looking after the home, in their social life and in their hobbies. Likewise, sleep alterations are relatively frequent in these patients. However, it must be emphasized that, after transplantation, the capacity of sleeping is much better than that before receiving the liver graft. Approximately $20 \%$ of the patients have intense insomnia, the mechanism of which has yet to be clarified (2,31). In a study by Belle and Porayko (28), QOL worsened in a subgroup of patients $(20 \%)$ after OLT, probably because of the increase in body pain and the complications of transplantation itself (rejection, immunosuppression, and post-transplant medical and surgical complications). On the other hand, the aspects related to family life significantly improved in all studies $(12,24)$. Hellgren et al (14) observed that patients who lived with their family had a much better QOL than those living alone. This result demonstrates the importance of family support in patients undergoing OLT, and indicates that family support for patients in the evaluation phase for entering a liver transplantation program is essential. Patients lacking family support must receive sufficient social support from the hospital itself.

Pain is relatively frequent in patients who receive liver transplants. The frequency of this complication ranges from $15 \%$ to $50 \%$, and its mechanism has not yet been established. Immunosuppression treatment, underlying liver disease, and the immobility or osteodystrophy often observed in liver patients, particularly those with chronic cholestasis (primary biliary cirrhosis and primary sclerosing cholangitis) probably play a very important role in the existence of pain, which obviously worsens the QOL of patients with transplants $(15,32)$. Of all the possible causes of pain, the most important is probably bone disease $(33,34)$.

Employment is an essential element of functional recovery and, therefore, of QOL (5). In addition, it has been demonstrated that QOL after OLT is related to income. Therefore, an important aim of OLT should be to allow the patient to return to his or her job (35). The normalization or improvement in QOL directly influences the patient's ca- pacity to return to work. The percentage of patients who return to work depends, among other things, on the type of social security available. Seiler et al (13) showed that, according to the criteria of the clinicians, more than $50 \%$ of patients who received liver transplants were able to carry out normal work activities. It has also been shown that, if the patients are retired (long term disease) before liver transplantation, the facilities for returning to the work market are reduced. Therefore, taking into account that returning to work improves the QOL, it may be deduced that work aspects should be included in the parameters used to evaluate patients for entering a liver transplantation program.

Evaluation of QOL may be considered one of the most important aspects to be analyzed by all members of the liver transplantation team (surgeons, hepatologists, psychologists, nurses and social workers), and will aid patients undergoing OLT to have a better QOL (25).

\section{COMPLICATIONS AND RECURRENCE OF DISEASE AFTER TRANSPLANTATION}

Complications: Although the aim of this overview is not to analyze deeply the complications of liver transplantation or the recurrence of the underlying liver disease, it is evident that both the complications and the recurrence of the disease have a great influence on the QOL perceived by these patients (36). The most frequent late complications (the immediate complications are not included because QOL is usually analyzed one year after OLT) in patients with liver transplants are briefly outlined below.

Chronic rejection: The incidence of chronic rejection has decreased in the past few years; currently, only $5 \%$ of patients with liver transplants present with this complication. The fundamental histological features are ductopenia and obliterative arteriopathy. The clinical picture corresponds to chronic cholestasis. For most patients, liver retransplantation is the only therapeutic solution (37).

Thrombosis of the hepatic artery: Thrombosis of the hepatic artery is observed in 1\% to $3 \%$ of patients and in most cases is an early complication. In the chronic forms, stenosis of the biliary tract with arterial ischemia develops. These patients present with clinical manifestations of chronic cholestasis, and most must receive a new transplant (38).

Thrombosis of the portal vein: Thrombosis of the portal vein occurs in $1.9 \%$ to $2.2 \%$ of patients. It usually occurs because of technical problems (excessive length and vein torsion, disproportion of the size of the vein between the donor and receptor). This complication results in portal hypertension, and there is a risk of gastric bleeding from rupture of esophageal varices after a certain length of time (39).

Biliary complications: Biliary complications have markedly diminished to only $8 \%$ to $10 \%$ in most centres. Many acute complications may be observed, and among the chronic complications (less frequent), stenosis of the biliary tract and secondary sclerosing cholangitis are noteworthy. Patients with these complications must undergo endoscopic dilation of the biliary tract, and in cases with little therapeutic response, retransplantation of the liver is recommended (40). 
Arterial hypertension: Seventy per cent of patients with liver transplants develop arterial hypertension. The cause of this complication is multifactorial, but the most important factor is immunosuppressive treatment (cyclosporin, tacrolimus). Associated renal dysfunction, steroid administration and concomitant hydrosaline retention, in addition to an increase in sympathetic tone, contribute to the pathogenesis of arterial hypertension. It is important to treat this complication to reduce the risk of hemorrhagic cerebrovascular accidents and hypertensive cardiopathy and nephropathy (41).

Neurological complications: The neurological complications observed in the first months after transplantation are very frequent and varied. Neurological and psychiatric complications are tremor, which usually starts during the earliest phases and is due to the effect of the immunosuppressive treatment, and psychosis and depression, which may, in part, result from corticosteroid use (42).

Renal failure: Chronic renal dysfunction occurs due to the toxic action of the immunosuppressors (cyclosporin, tacrolimus) and may be seen in $50 \%$ of patients the first year after transplantation, with a variable clinical evolution. From a histological point of view, a tubulointerstitial lesion of irreversible character may lead to the need for renal transplantation (41).

Infectious complications: Infectious complications are very frequent during the first days after transplantation because of the surgery itself and the initiation of immunosuppressive treatment. However, six months after transplantation, the risk of infection is similar to that of the general population; these infections are almost always of a respiratory nature. In any case, the risk of severe late opportunistic infections never disappears, especially in patients who have received very intense immunosuppressive treatment (43).

Metabolic complications: The immunosuppressive medication that patients with liver transplants must take provokes numerous metabolic complications. Up to two-thirds of liver graft recipients develop obesity, in part, because of the increase in appetite stimulated by the corticosteroids, because of the subjective sensation of good health and, fundamentally, because of normalization of the metabolic functions of synthesis (44).

Resistance to insulin and diabetes mellitus are very frequent. As a consequence of immunosuppressive treatment, $10 \%$ to $25 \%$ of patients with liver transplants present with diabetes mellitus one year after transplantation. However, the prevalence of diabetes progressively decreases after OLT. There is no definitive evidence that diabetes mellitus worsens QOL (45).

Cyclosporin A increases cholesterol synthesis, while obesity, and the use of corticosteroids, diuretics and beta-blockers favours and aggravates dyslipemia. Approximately 40\% of patients with liver transplants have hypercholesterolemia and hypertriglyceridemia. We, therefore, recommend moderate exercise and avoidance of fat-rich diets to all of our patients with liver transplants. In some cases, pharmacological treatment with hypolipemic drugs is required (46).

The hepatic osteodystrophy that affects most patients before transplantation continues and even becomes more severe in the first months after transplantation. Forty per cent of patients with liver transplants develop osteodystrophy associated with pathological fractures. While the clinical situation before OLT is a main factor in the development of hepatic osteodystrophy, immobility and the use of steroids after OLT are also factors in the development of this disease. Perhaps the main recommendations are to prevent hepatic osteodystrophy, and to have patients perform moderate exercise and take calcium and vitamin D before and after OLT $(34,47)$. Antiresorptive therapies after transplantation should be assayed in prospective, controlled trials.

De novo tumours: Patients with liver transplants have a higher risk of developing tumours than the general population. This complication is a long term consequence of the immunosuppressive medication. The most frequent de novo tumours are lymphomas and cutaneous tumours. The development of other tumours such as Kaposi sarcoma, colon cancer, lung cancer, and cancer of the vulva and cervix have also been detected (48).

Recurrence: The primary liver disease recurs very frequently after liver transplantation, particularly in patients with liver diseases of viral origin.

Hepatitis B: Recurrence of hepatitis B is frequent, and has severe consequences and a poor prognosis; $50 \%$ of patients die within five years after transplantation. Viral recurrence is observed in $90 \%$ to $100 \%$ of patients with active viral replication. These patients are excluded as liver transplant recipients, although lamivudine would open new possibilities for them by blocking viral replication. In cases of viral replication, recurrence of hepatitis B has a high frequency (around $80 \%$ ) if prophylactic treatment comprising high doses of intravenous gammaglobulin antihepatitis B are not given in the long term. A combination therapy comprising lamivudine and hepatitis B immune globulins is being evaluated. The consequences of viral recurrence vary, and range from a hepatitis B carrier state to fulminant graft failure. The evolution to cirrhosis is usually very rapid (within months). A special form of recurrence is cholestatic fibrosing hepatitis; the prognosis is very poor and all patients develop hepatic insufficiency (49).

Hepatitis D virus infection recurs in most patients who undergo transplantation for this indication, but hepatitis does not always develop. It develops in $30 \%$ to $50 \%$ of cases and is associated with time of recurrence of hepatitis $B$ virus infection. The prognosis is not as poor, with up to $80 \%$ survival reported at five years (50).

Hepatitis C: Hepatitis C infection recurs in $100 \%$ of patients after liver transplantation. The $1 \mathrm{~b}$ genotype is associated with more frequent recurrence and is more histologically active. The middle term prognosis is good, and the survival curves are similar to those obtained for other indications. However, $20 \%$ to $50 \%$ of the patients develop more severe forms of the disease within one to three years, leading to hepatic insufficiency. Interferon treatment is not effective (51).

Alcohol: The factors that determine the risk of returning to 
drinking alcohol are the psychiatric evaluation, the sociofamilial environment of the patient before transplantation, good family support and a stable work situation. The rate of recurrence ranges from $9 \%$ to $33 \%$. A six-month abstinence reduces the rate of recurrence (52). In patients with severe alcoholic hepatitis, transplantation without the prerequisite six-month abstinence was found to result in good survival, without an increase in the incidence of alcoholic recurrence (53).

Hepatocellular carcinoma: Post-transplant recurrence of hepatocellular carcinoma has drastically decreased to less than $10 \%$ in all liver transplantation programs because of appropriate receptor selection (54).

Primary biliary cirrhosis: Recurrence of primary biliary cirrhosis remains a topic of discussion and debate $(55,56)$; it is very infrequent and is usually benign.

Other diseases: Primary sclerosing cholangitis, autoimmune hepatitis, the Budd-Chiari syndrome and erythropoietic protoporphyria, may also recur, although infrequently (1).

\section{SUMMARY AND FUTURE TRENDS}

In most patients, QOL improves after transplantation, although in some cases it may worsen. One of the symptoms that most often worsens is pain, which, undoubtedly, may re-

\section{REFERENCES}

1. Balan V, Marsh JW, Rakela J. Liver transplantation. In: Bircher J, Benhamou JP, McIntyre N, Rizzetto M, Rodés J, eds. Clinical Hepatology. Oxford: Oxford Medical Publications, 1999:2039-63.

2. Tarter RE, Switala J, Arria A, Plail J, Van Thiel D. Quality of life before and after orthotopic hepatic transplantation. Arch Intern Med 1991;151:1521-6.

3. Leplège $A$, Hunt $S$. The problem of quality of life in medicine. JAMA 1997;278:47-50.

4. Walsh RM, Aranha GV, Freeark RJ. Mortality and quality of life after total abdominal colectomy. Arch Surg 1990;125:1564-6.

5. Patrick DL, Bergner M. Measurement of health status in the 1990s. Annu Rev Public Health 1990;11:165-83.

6. Guyatt GH, Feeny DH, Patrick DL. Measuring health-related quality of life. Ann Intern Med 1993;118:622-9.

7. Torrance GW. Measurement of health state utilities for economic appraisal. J Health Econ 1986;5:1-30.

8. Wilson IB, Cleary PD. Linking clinical variables with health-related quality of life. JAMA 1995;273:59-65.

9. Lundgren M, Kristiansson BG, Eleborg L. Improved quality of life after liver transplantation. Transplant Proc 1994;26:1779.

10. Hicks FD, Larson JL, Ferrans CE. Quality of life after liver transplant. Res Nurs Health 1992;15:111-9.

11. Adams PC, Chent CN, Grant DR, Wall WI. Employment after liver transplantation. Hepatology 1995;21:140-4.

12. Navasa M, Forns X, Sánchez V, Andreu H, Marcos V, Borrás JM. Quality of life, major medical complications and hospital service utilization in patients with primary biliary cirrhosis after liver transplantation. J Hepatol 1996;25:129-34.

13. Seiler CA, Müller M, Fisch HU, Renner EL. Quality of life after liver transplantation. Transplant Proc 1998;30:4330-3.

14. Hellgren A, Berglund B, Gunnarsson U, Hansson K, Norberg U, Bäckman L. Health-related quality of life after liver transplantation. Liver Transpl Surg 1998;4:215-21.

15. Zigmond AS, Snaith RP. The hospital anxiety and depression scale. Acta Psychiatr Scand 1983;67:361-70.

16. Beck AT, Ward CH, Mendelson M. An inventory for measuring depression. Arch Gen Psychiatry 1961;6:561-72.

17. Singh N, Gayowski, Wagener MM, Marino IR. Quality of life, functional status and depression in male liver transplant recipients with recurrent viral hepatitis C. Transplantation 1999;67:69-72.

18. McNair DM, Goldstein AP, Lorr M, Cibelli LA, Roth I. Some effects sult in a worse QOL after liver transplantation. A number of factors can result in a decreased QOL - notably, recurrence of the underlying liver disease; complications that appear in the long term, especially vascular and biliary diseases, neurological alterations, arterial hypertension and hepatic osteodystrophy; and the absence of family support, income and employment.

To improve QOL further, we recommend

- incorporation of psychologists, social workers and support nurses to the liver transplantation teams;

- improvement in surgical technique (if possible) to reduce post-transplant vascular and biliary complications to the minimum;

- development of new immunosuppressant drugs with fewer side effects;

- investigation of the mechanisms of osteodystrophy and its treatment;

- discovery of new antiviral agents that are effective in avoiding viral recurrence; and

- more prospective clinical research on the QOL in more homogenous groups of patients with liver disease in liver transplantation programs.

of chlordiazepoxide and meprobromate with psychiatric outpatients. Psychopharmacology 1965;7:256-75.

19. Belle SH, Porayko MK, Hoofnagle JH, Lake JR, Zetterman RK. Changes in QOL after liver transplantation in adults. Liver Transpl Surg 1997;3:93-104.

20. Wiesner RH, Krom RAF. Twelve years of liver transplantation in the Mayo Clinic. In: Teraski CA, ed. Clinical Transplants. Los Angeles: UCLA Tissue Typing Laboratory, 1997:173-81.

21. Diener E. Subjective well-being. Psychol Bull 1984;95:542-75.

22. Levy MF, Jennings L, Aboulijoud SM, et al. Quality of life improvements at one, two and five years after liver transplantation. Transplantation 1995;59:515-8.

23. Ware JE. Conceptualizing disease impact and treatment outcomes. Cancer 1984;53(10 Suppl):2316-23.

24. Gross CR, Malinchoc M, Kim R, et al. Quality of life before and after liver transplantation for cholestatic liver disease. Hepatology 1999;29:356-64.

25. Küchler T. Liver transplantation: Quality of life related prognosis. Transplant Proc 1999;31:1404-5.

26. Goff JS, Glazner J, Bilir BM. Measuring outcome after liver transplantation: a critical review. Liver Transplant Surg 1998;4:189-96.

27. Guyatt GH, Naylor CD, Juniper E, Heyland DK, Jaeschke R, Cook DJ. Users' guide to the medical literature. XII. How to use articles about health-related quality of life. JAMA 1997;277:1232-7.

28. Belle SH, Porayko MK. Improvement in quality of life after transplantation for the recipients in the NIDDK Transplantation Database. Transpl Proc 1995;27:1230-2.

29. Gelling L. Quality of life following liver transplantation: physical and functional recovery. J Adv Nursing 1998;28:779-85.

30. Collis I, Burroughs A, Rolles K, Lloyd G. Psychiatric and social outcome of liver transplantation. Br J Psychiatry 1995;166:521-4.

31. Price CE, Lowe D, Cohen AT, et al. Prospective study of QOL in patients assessed for liver transplantation: outcome in transplanted and not transplanted groups. J R Soc Med 1995;88:130-5.

32. Bonsel GJ, Essink-Bot ML, Klompmaker IJ, Sloof MJH. Assessment of the quality of life before and following liver transplantation. Transplantation 1992;53:796-800.

33. Nicholas JJ, Oleske D, Robinson LR, Switala JA, Tarter R. The quality of life after orthotopic liver transplantation: An anlysis of 166 cases. Arch Phys Med Rehab 1994;75:431-5. 
34. Navasa M, Monegal A, Guañabens N, et al. Bone fractures in liver transplant patients. Br J Rheumatol 1994;33:52-5.

35. Flanagan JC. Measurement of quality of life: current state of the art. Arch Phys Med Rehab 1982;63:56-9.

36. LoBiondo-Wood G, Williams L, Wood RP, Shaw BW. Impact of liver transplantation on quality of life: a longitudinal perspective. Appl Nurs Res 1997;10:27-32.

37. Backman L, Dyer C, Dyer CH, Laberge JM, Ostroff JW, Shaw BW. Causes of late graft loss after liver transplantation. Transplantation 1993;55:1078-82.

38. Tzakis AG, Gordon RD, Shaw BW, Iwazutki S, Starzl TE. Clinical presentation of hepatic artery thrombosis after liver transplantation in the cyclosporine era. Transplantation 1985;40:667-71.

39. Lerut J, Tzakis AG, Bron K, et al. Complication of venous reconstruction in human orthotopic liver transplantation. Ann Surg 1987;205:404-14.

40. LaBerge JM, Ostroff JW. Non-operative management of biliary tract complications after liver transplantation. Semin Gastrointest Dis 1993;4:170-7.

41. Monsour HP Jr, Wood RP, Dyer CH, Galati JS, Ozaki CF, Clark JH. Renal insufficiency and hypertension as long-term complications in liver transplantation. Semin Liver Dis 1995;15:123-32.

42. Stein DP, Lederman RJ, Vogt DP, Carey WD, Broughan TA. Neurological complications following liver transplantation. Ann Neurol 1992;31:644-9.

43. Domínguez EA. Long-term infections complications of liver transplantation. Semin Liver Dis 1995;15:133-8.

44. Muñoz S, Deems R, Moritz M, Martin P, Jarrell BE, Maddrey WC. Hyperlipidemia and obesity after orthotopic liver transplantation. Transplant Proc 1991;23:1480-3.

45. Navasa M, Bustamante J, Marroni C, et al. Diabetes mellitus after liver transplantation: prevalence and predictor factors. J Hepatol 1996;25:64-71.
46. Muñoz SJ. Hyperlipidemia and other coronary factors after orthotopic liver transplantation: Pathogenesis, diagnosis and management. Liver Transpl Surg 1995;1(Suppl 1):29-38.

47. Monegal A, Navasa M, Guañabens N, et al. Osteoporosis and bone mineral metabolism disorders in cirrhotic patients referred to orthotopic liver transplantation. Calcif Tissue Int 1997;60:148-54.

48. Tan-Shaleby J, Tempero M. Malignancies after liver transplantation: a comparative review. Semin Liver Dis 1995;15:156-64.

49. Crippin J, Foster B, Carlen S, Borcich A, Bodenheimer H Jr. Retransplantation in hepatitis B. A multicenter experience.Transplantation 1994;57:823-6.

50. Samuel D, Ziznego AL, Reynes M, et al. Long-term clinical and virological outcome after liver transplantation for cirrhosis caused by chronic delta hepatitis. Hepatology 1995;21:333-9.

51. Singh N, Gayowski T, Wagener MM, Marino IR. Quality of life, functional status, and depression in male liver transplant recipients with recurrent viral hepatitis $\mathrm{C}$. Transplantation 1999;67:69-72.

52. Sherman D, Williams R. Liver transplantation for alcoholic liver disease. J Hepatol 1995;23:474-9.

53. Shakil, AO, Pinna A, Demetris J, Lee RG, Fung JJ, Rakela J. Survival and quality of life after liver transplantation for acute alcoholic hepatitis. Liver Transpl Surg 1997;3:240-4.

54. Yokoyama IN, Carr B, Saitsu S, Iwatsuki S, Starzl TE. Accelerate growth rates of recurrent hepatocellular carcinoma after liver transplantation. Cancer 1992;20:2263-7.

55. Balan V, Batts K, Porayko MK, Krom RAF, Jurgen L, Wiesner RH. Histological evidence for recurrence of primary biliary cirrhosis after liver transplantation. Hepatology 1993;18:1392-8.

56. Gouw AJM, Haajsma EB, Manns M, Klompmaker IJ, Slooff MJ, Gerber MA. Is there recurrence of primary biliary cirrhosis after liver transplantation? Hepatology 1994;50:500-7. 


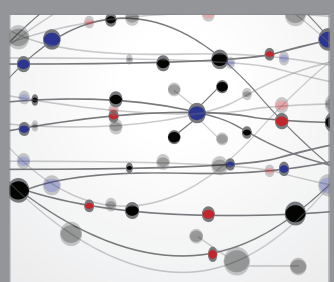

The Scientific World Journal
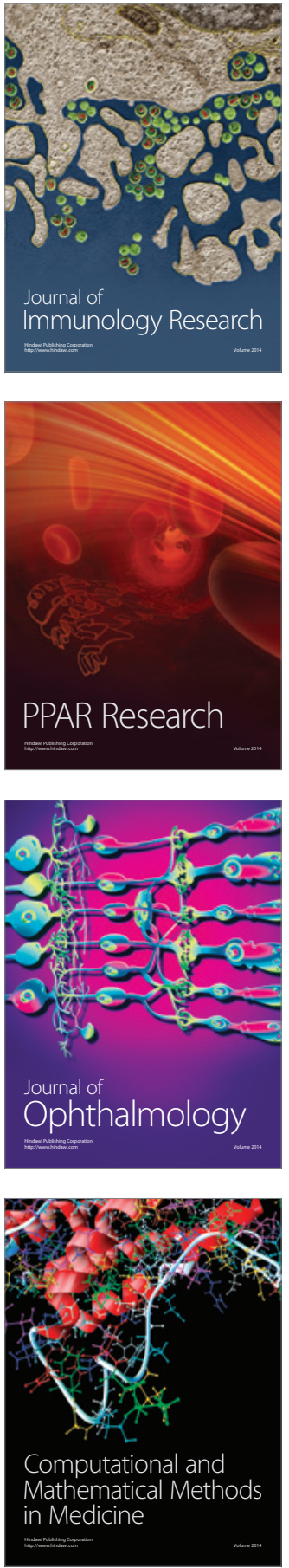

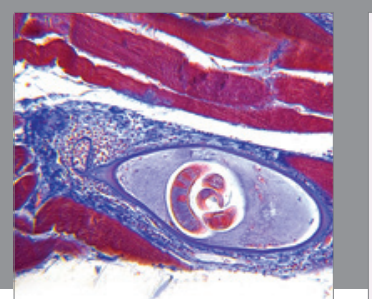

Gastroenterology Research and Practice

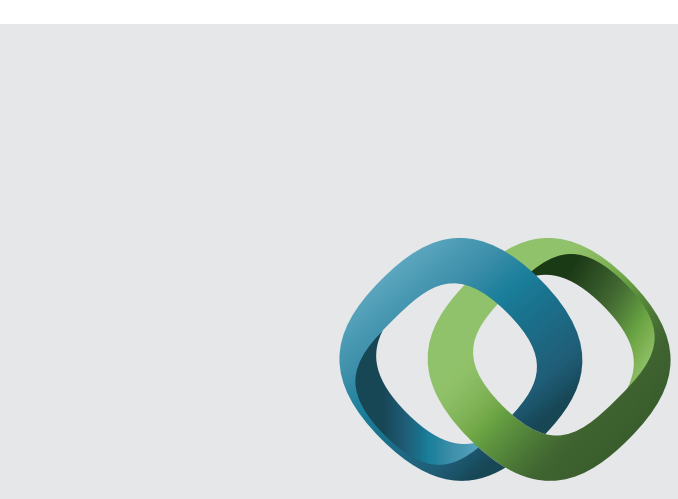

\section{Hindawi}

Submit your manuscripts at

http://www.hindawi.com
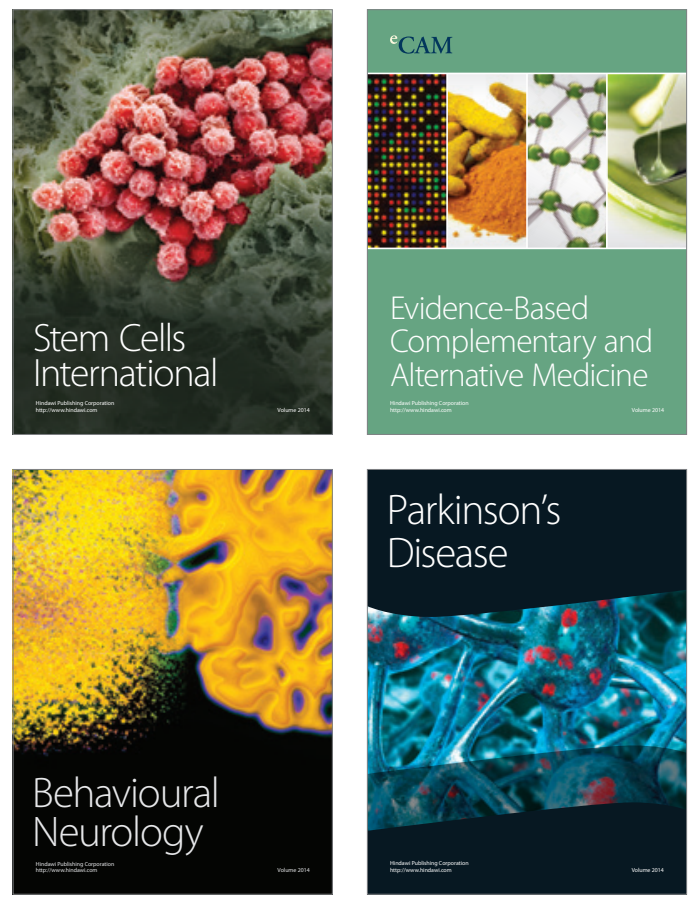
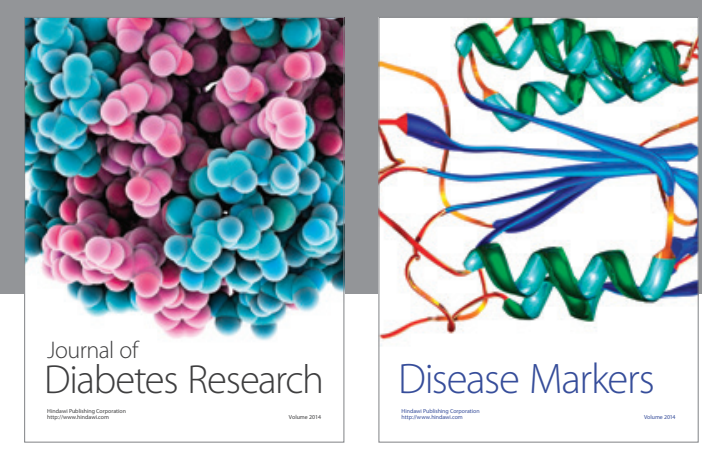

Disease Markers
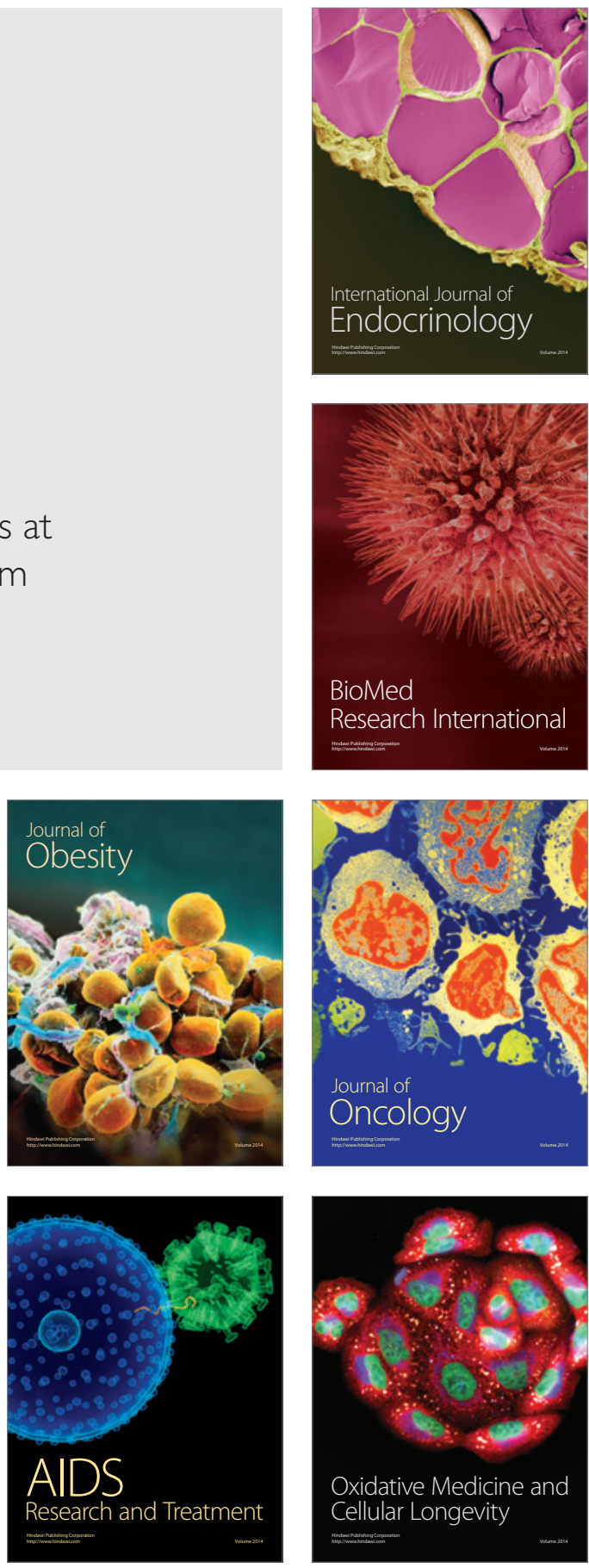